\title{
Relação entre solo, vegetação e topografia em área de cerrado (Parque Estadual de Vassununga, SP): como se expressa em mapeamentos?
}

\author{
Patricia Guidão Cruz Ruggiero ${ }^{1}$, Vânia Regina Pivello ${ }^{1,4}$, Gerd Sparovek ${ }^{2}$, Edson Teramoto ${ }^{2}$ e \\ Antônio Gonçalves Pires Neto ${ }^{4}$
}

Recebido em 29/03/2005. Aceito em 26/09/2005

\begin{abstract}
RESUMO - (Relação entre solo, vegetação e topografia em área de cerrado (Parque Estadual de Vassununga, SP): como se expressa em mapeamentos ?). Foram investigadas as relações entre mapas de fitofisionomias, solos e topografia, na Gleba Pé-de-Gigante (21³7’30”S; 47³7’30'W, SP). A área estudada constitui a planície de inundação do córrego Paulicéia e colinas no entorno, onde predominam fisionomias de cerrado, havendo também manchas de floresta estacional, floresta ripária e campo úmido, sobre solos predominantemente arenosos. As cartas temáticas analisadas compreenderam: a) mapa pré-existente de fisionomias de vegetação, b) mapa hipsométrico, baseado em curvas de nível de $5 \mathrm{em} 5 \mathrm{~m} \mathrm{e} \mathrm{c)} \mathrm{mapa} \mathrm{de} \mathrm{solos,} \mathrm{feito} \mathrm{a} \mathrm{partir} \mathrm{de} \mathrm{dados} \mathrm{químicos} \mathrm{e} \mathrm{físicos} \mathrm{do} \mathrm{solo} \mathrm{(amostras} \mathrm{coletadas} \mathrm{em} 54$ pontos, nas profundidades: 0-5, 5-25, 40-60 e 80-100 cm) e fotografias aéreas (1988, 1:40.000). Os mapas foram re-classificados, para se obter diferentes níveis de detalhamento, e cruzados, em sistema de informação geográfica. Nas tabelas de contingência, geradas a partir dos cruzamentos, foi aplicado o teste de Qui-quadrado e obtido o valor de correlação de Cramér, para investigar a relação entre os mapeamentos. A floresta estacional semidecídua se mostrou fortemente associada à classe geral de Latossolos, e o campo cerrado às altitudes de 620-650 m, provavelmente associado à dinâmica sub-superficial da água. O detalhamento da informação mapeada nos temas analisados não garantiu melhores resultados à interpretação de suas relações, pois as classes fitofisionômicas não respondem diretamente, nem isoladamente, à topografia ou à classificação usual dos solos.
\end{abstract}

Palavras-chave: cerrado, fitofisionomia, classificação de solos, topografia, mapeamento, correlação espécie-ambiente

\begin{abstract}
The relationship among soil, vegetation and topography in a cerrado area (Vassununga State Park, SP): how well is it expressed in maps ?). Relationships among vegetation, soil and topography maps were investigated in the Pé-de-Gigante Reserve $\left(21^{\circ} 37^{\prime} 30^{\prime \prime} \mathrm{S} ; 47^{\circ} 37^{\prime} 30^{\prime \prime} \mathrm{W}, \mathrm{SP}\right)$. The studied area is the Paulicéia river basin, where soils are predominantly sandy and the vegetation includes a gradient of savanna physiognomies and patches of semideciduous forest, wet fields, and riparian forest. The cartographic material included: a) pre-existent vegetation map, b) topographic map based on $5 \mathrm{~m}$ contour curves, and c) a soil map based on chemical and physical soil features (soil samples collected at 54 sites at 0-5, 5-25, 40-60 e 80-100 cm depths) and aerial photographs (1988, 1:40.000). These maps were reclassified to generate secondary maps at different levels of detail, and overlayed through a geographic information system. Contingency tables were generated, and chi-squared values and Cramér correlation coefficients were obtained to investigate the relationships between the maps. The semideciduous forest showed a strong correlation with the Oxissols; "campo cerrado" was associated to 620-650 m altitudes, probably due to sub-surface water dynamics. The refinement of the mapped information did not add to the interpretation of the relationships among soil, vegetation and topography, as the vegetation physiognomy does not respond directly nor independently to topography or to the usual soil classification.
\end{abstract}

Key words: cerrado, vegetation forms, soil classification, mapping, species-environment correlation

\section{Introdução}

O Cerrado, segundo maior bioma brasileiro, apresenta alta diversidade em espécies vegetais e em fitofisionomias, abrangendo desde fisionomias campestres, como o campo limpo, até florestais, como o cerradão, e passando por formas intermediárias, como o campo sujo, campo cerrado e cerrado sensu stricto (Coutinho 1978; Castro et al. 1999), num gradiente de elementos lenhosos. Essa diversidade fitofisionômica tem sido relacionada à variação de características edáficas, dentre elas, principalmente a disponibilidade

\footnotetext{
1 Departamento de Ecologia, Instituto de Biociências, Universidade de São Paulo, Rua do Matão, Travessa 14, CEP 05508-900, São Paulo, SP, Brasil

2 Universidade de São Paulo, Escola Superior de Agricultura Luiz de Queiroz, Departamento de Ciência do Solo e Nutrição de Plantas, CEP 13418-900, Piracicaba, SP, Brasil

3 Universidade de Guarulhos, Laboratório de Geociências, Guarulhos, SP, Brasil

4 Autor para correspondência: vrpivel@usp.br
} 
de nutrientes e o teor de alumínio no solo (Alvim \& Araújo 1952; Goodland \& Pollard 1973; Ratter et al. 1977; Silva Júnior et al. 1987). Alguns autores também sugeriram uma relação entre fitofisionomias e a variação das formas de relevo e topografia (Gibbs et al. 1983; Oliveira Filho \& Martins 1986; Furley \& Ratter 1988; Oliveira Filho et al. 1989; Furley 1996), bem como à dinâmica da água no solo (Oliveira Filho \& Martins 1986; Oliveira Filho et al. 1989; Oliveira Filho et al. 1997). No entanto, a maioria desses trabalhos baseou-se em coletas pontuais ou ao longo de transeções, relacionando a variação das características fisiográficas às comunidades vegetais. Os resultados obtidos foram, muitas vezes, contraditórios.

Uma nova abordagem para estas questões ecológicas surgiu com a possibilidade de se trabalhar com as relações entre elementos da paisagem, utilizando informação espacializada. A forma mais usual de representação da informação espacial é por meio de mapas. Eles permitem visualizar áreas ou fenômenos específicos e perceber conexões, padrões e estruturas referentes ao objeto mapeado (Kraak \& Ormeling 1996).

Em mapeamentos, assume-se que cada área delimitada (classe) seja uniforme e, portanto, que os valores de uma determinada variável sejam constantes dentro da mesma classe (Burrough 1995). Existe, porém, uma relação entre a variabilidade incorporada em cada classe - ou seja, a heterogeneidade considerada - e a escala de representação do objeto. Assim, numa mesma região, espera-se que mapas em maior detalhe (ou em menor escala) possuam um maior número de classes e uma menor variação dentro de cada classe, quando comparados a mapas em menor detalhe (maior escala).

A heterogeneidade do solo e a da comunidade vegetal são percebidas e quantificadas de maneiras distintas. Em levantamentos de solos, comumente são feitas observações pontuais, distribuídas ao longo de diferentes unidades do relevo. Para o mapeamento da vegetação, a obtenção de dados contínuos é mais acessível, principalmente por meio de sensores remotos, como fotografias aéreas e imagens de satélite.

$\mathrm{O}$ uso de informações remotamente obtidas difundiu-se muito com o desenvolvimento dos sistemas de informação geográfica (SIGs). Tais sistemas gerenciam a informação espacial e permitem sobrepor mapas de diferentes temas, relacionando e integrando as informações e, assim, facilitando a percepção de padrões e relações entre eles. Ao se utilizar os SIGs, porém, é necessário ter ciência de como os mapas iniciais foram gerados. Por exemplo, para a delimitação de classes de solo na produção de um mapa pedológico, geralmente se usa as cotas altitudinais e o aspecto da vegetação. Essa informação deve ser considerada ao se estabelecer relações entre tais elementos da paisagem, na interpretação de suas correlações.

Neste estudo, foram comparados mapas de vegetação com mapas de solo e topográficos, em diferentes níveis de detalhe, a fim de analisar a coincidência entre as classes delimitadas em cada um desses temas e detalhamentos e, conseqüentemente, a relação entre os temas. Seguiu-se a seguinte hipótese de trabalho: as classes delimitadas no mapa de vegetação, em diferentes níveis de detalhamento, coincidem com as classes de solo e/ou topografia, em níveis correspondentes de detalhe.

\section{Material e métodos}

Área de estudo - Este estudo foi realizado na Gleba Cerrado Pé-de-Gigante, com aproximadamente 1.225 ha e coordenadas geográficas centrais de

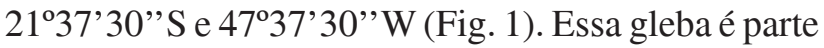
do Parque Estadual de Vassununga (Santa Rita do Passa Quatro, SP) (Pivello et al. 1999).

O clima regional é tropical do tipo II (Walter 1986), ou Cwa (Köppen 1948), com período seco nos meses de abril a setembro (Martins 1982). Geadas podem ocorrer nos meses de inverno (junho a agosto).

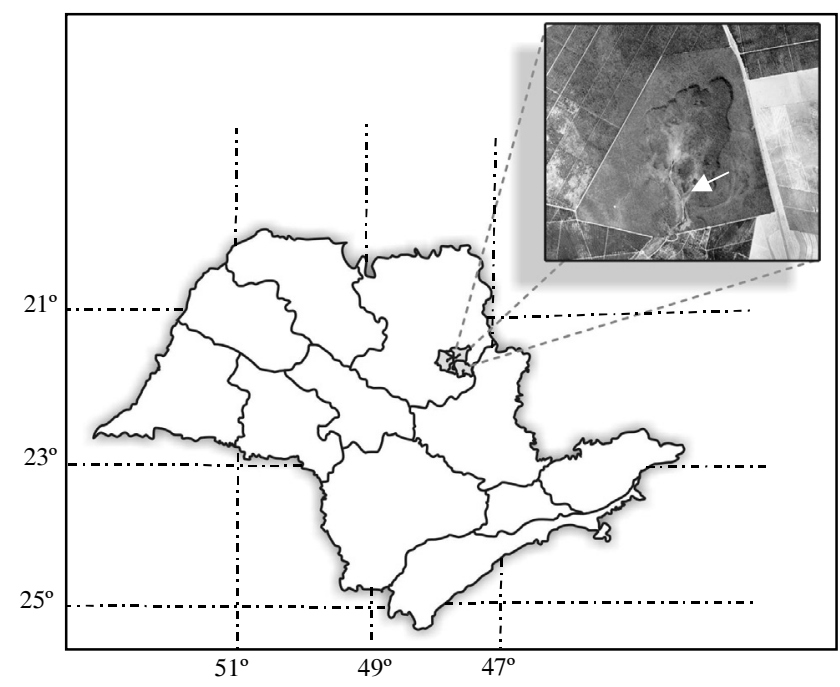

Figura 1. Esquema de localização da Gleba Cerrado Pé-de-Gigante (Santa Rita do Passa Quatro, SP) no Estado de São Paulo. Em detalhe, foto aérea da área, onde se observa a depressão em forma de uma pegada humana, que dá nome à Reserva, e o córrego Paulicéia, que a corta, apontado pela seta branca. 
Na região, o relevo é colinoso, sendo que colinas amplas predominam nos divisores de águas e colinas pequenas nas áreas mais dissecadas pela drenagem. Esse padrão é seguido na Gleba Pé-de-Gigante: o divisor de águas da bacia do córrego Paulicéia, que corta a Gleba (altitudes de 660 a $740 \mathrm{~m}$ ), é caracterizado por colinas amplas, com encostas suaves (inclinações de $2 \%$ a $5 \%$ ), sustentadas por arenitos das formações Botucatu e Santa Rita ou, secundariamente, da formação Pirambóia. As colinas pequenas, que caracterizam a porção central da Gleba (altitudes de 590 a $665 \mathrm{~m}$ ), apresentam encostas com inclinações de $5 \%$ a $15 \%$, sustentadas por arenitos da formação Pirambóia e, localmente, por basaltos e diabásios da formação Serra Geral. A zona de contato entre as colinas amplas e as pequenas é marcada por encostas mais inclinadas, que podem apresentar escarpas descontínuas, com amplitudes de 20 a $30 \mathrm{~m}$ e inclinações de 20 a 32\%. As planícies fluviais estreitas, descontínuas e com áreas alagadiças, são constituídas por areia fina, silte, argila e matéria orgânica (Pivello et al. 1999).

O Parque Estadual de Vassununga encontra-se numa região transicional entre os biomas Cerrado e Mata Atlântica e, na Gleba Pé-de-Gigante, apesar de predominarem fisionomias de cerrado, há uma mancha significativa de floresta estacional semidecídua. Há também uma pequena mancha de floresta ripária, ao longo do córrego Paulicéia. As seguintes fitofisionomias foram definidas para a área de estudo: floresta estacional semidecídua, cerradão, cerrado sensu stricto com estrato herbáceo ralo, campo sujo de encosta, campo limpo com predominância de Melinis minutiflora (capim gordura), campo úmido com predomínio de Andropogon spp., campo úmido com predomínio de Pteridium sp. e floresta ripária (Pivello et al. 1999; Batalha et al. 2002). Os solos predominantes são os Neossolos Quartzarênicos, anteriormente denominados Areias Quartzosas (Oliveira et al. 1992; EMBRAPA 1999), com teores baixos de argila, bem como os Latossolos.

Mapas - A carta base utilizada foi um mapa topográfico, com curvas de nível de 5 em $5 \mathrm{~m}$, produzido a partir das cartas topográficas do IBGE na escala 1:50.000 (IBGE 1971), do DER, na escala 1:20.000 (DER s.d.) e IGC, na escala 1:10.000 (IGC 1990), em sistema de informação geográfica (IDRISI 1997) (Bitencourt \& Pivello 1998; Pivello et al. 1999). Os mapas temáticos analisados foram: um mapa préexistente de fisionomias de vegetação (Pivello et al. 1999; Batalha et al. 2002), produzido a partir da interpretação de fotografias aéreas (1988, escala 1:40.000), imagens de satélite LANDSAT TM-3 e TM-4 e verificações em campo, além de um mapa hipsométrico e um mapa de solos, produzidos conforme descrito a seguir.

O mapa de solos, em escala de semi-detalhe, foi feito a partir da análise das características de solo coletado em 54 pontos, a 0-5, 5-25, 40-60 e 80-100 cm de profundidade. A fim de garantir a amostragem da maior variedade possível de solos nesta escala, os pontos de coleta foram estratificados e distribuídos homogeneamente em unidades de mapeamento, definidas por pedólogo, principalmente com base nas formas do relevo presentes na área (encosta, reverso da encosta, colina, morrote, planície fluvial, grota da floresta estacional). Foram determinados os seguintes atributos químicos e físicos do solo: matéria orgânica total, $\mathrm{pH}$ em água e $\mathrm{CaCl}_{2}$, fósforo disponível às plantas, cálcio, potássio, magnésio e alumínio trocáveis, soma de bases, saturação por alumínio e por bases, capacidade de troca cationnica, bem como a textura (conforme Camargo et al. 1986 e Raij et al. 1987), e cor (U.S. Dept. Agriculture 1994). Com base na relação conhecida entre a gênese dos solos e os processos geomorfológicos (Cole 1982; 1986; Furley \& Ratter 1988; Furley 1996), os limites das classes de solo foram traçados respeitando-se as linhas do relevo identificadas por meio da interpretação de fotografias aéreas (1988, escala 1:40.000). Em nenhum momento foram utilizados os limites da vegetação para delimitar os limites das classes de solo, ainda que este seja um procedimento comum entre pedólogos.

A partir da carta topográfica, foi calculado o modelo numérico do terreno, pela interpolação das curvas de nível, que resultou numa superfície contínua de valores de altitude. Esse modelo foi utilizado para a produção dos mapas hipsométricos.

Os mapas de solos, vegetação e hipsometria foram re-classificados, agrupando-se classes para a obtenção de diferentes níveis de detalhamento. No caso das classes de solo, utilizou-se os níveis taxonômicos como critério de agrupamento, tendo-se obtido dois níveis de detalhe: SOLO1, mais detalhado, e SOLO2. A vegetação foi agrupada conforme três níveis de detalhe: VEGE1, contendo as 10 fitofisionomias propostas em Pivello et al. (1999); VEGE2, com 7 classes conforme Coutinho (1978) e VEGE3, com apenas os três tipos fisionômicos, conforme Eiten (1987) (Tab. 1). O número de classes altitudinais em cada mapa hipsométrico foi determinado de forma que fossem compatíveis com o número de classes de solo e 
Tabela 1. Classes de vegetação para os mapeamentos em diferentes níveis de detalhe (VEGE1, VEGE2, VEGE3) feitos para a Gleba Cerrado Pé-de-Gigante.

\begin{tabular}{|c|c|c|}
\hline \multicolumn{3}{|c|}{ Mapeamentos e respectivas classes } \\
\hline VEGE1 & VEGE2 & VEGE3 \\
\hline Pivello et al. (1999) & Coutinho (1978) & Eiten (1987) \\
\hline \multirow{10}{*}{$\begin{array}{c}\text { floresta ripária } \\
\text { floresta estacional semidecídua } \\
\text { cerradão } \\
\text { cerrado sensu stricto com estra } \\
\text { cerrado sensu stricto } \\
\text { campo cerrado } \\
\text { campo sujo de encosta } \\
\text { campo de Andropogon spp. } \\
\text { campo de Pteridium sp. } \\
\text { campo de Melinis minutiflora }\end{array}$} & floresta ripária & floresta \\
\hline & floresta estacional semidecídua & \\
\hline & cerradão & cerrado sensu lato \\
\hline & & \\
\hline & cerrado sensu stricto & \\
\hline & campo cerrado & \\
\hline & campo sujo & \\
\hline & campo úmido & campo úmido \\
\hline & & \\
\hline & & \\
\hline
\end{tabular}

vegetação, nos respectivos mapas. Assim, foram compostos três mapas hipsométricos em diferentes níveis de detalhamento: HIPS1, com 8 classes, HIPS2, com 6 classes e HIPS3, com 4 classes.

Os mapas de vegetação foram cruzados com os mapas de solos e topografia aos pares, compreendendo todas as combinações possíveis, com exceção de pares de mapas de um mesmo grupo temático (por exemplo, VEGE1 × VEGE2). Cada cruzamento resultou numa tabela de contingência, que apresenta a área de interseção entre as classes cruzadas, nas quais cada mapa foi considerado como uma variável. A associação entre as variáveis da tabela foi verificada pelo teste do Qui-quadrado $\left(\chi^{2}\right)$ (Zar 1999). No caso de valores de $\chi^{2}$ significativos, foi calculado o coeficiente de correlação de Cramér $(\phi)$ (Zar 1999). Este coeficiente varia de zero a um e foi utilizado como indicativo de associação entre as variáveis cruzadas. Os cruzamentos que apresentaram os maiores valores de $\phi$ para cada conjunto de mapas temáticos foram analisados quanto à porcentagem de contribuição de cada classe para o valor do $\chi^{2}$ final, com base na diferença entre o observado e o esperado (quanto maior a diferença entre esperado e observado, maior a porcentagem de contribuição da classe e, portanto, maior associação entre as variáveis).

Todos os procedimentos de produção e cruzamento de mapas foram feitos por meio do programa IDRISI (versão 2, 1997).

Os resultados da análise cartográfica também foram apresentados em um perfil topográfico, no qual procurou-se integrar as informações sobre a vegetação, os solos e o relevo.

\section{Resultados}

$\mathrm{Na}$ área de estudo, predominaram os Neossolos Quartzarênicos, com teores baixos de argila, os quais foram divididos em três classes: RQo1 álico = Neossolo Quartzarênico órtico típico álico, relevo suave-ondulado a ondulado, RQo2 eutrófico = Neossolo Quartzarênico órtico típico eutrófico, relevo plano a suave-ondulado, e RQg + RUbd = Neossolos Quartzarênicos Hidromórficos típicos e Flúvicos Tb eutróficos, textura arenosa a média (Fig. 2A). Os Neossolos do Cerrado Pé-de-Gigante apresentam perfil homogêneo, horizonte A fraco e coloração variando de marrom escuro a marrom escuro amarelado e acizentada, no caso dos hidromórficos típicos. Também são encontradas, com menor expressão, duas classes de Latossolo: LVd - Latossolo Vermelho, textura argilosa e LVAd - Latossolo Vermelho-Amarelo, textura média (Fig. 2A). Estas se mostraram, de forma geral, distróficas e álicas, com perfil homogêneo, horizonte A moderado e pequeno acréscimo de argila com o aumento da profundidade.

As características químicas (matéria orgânica, $\mathrm{pH}$, Al trocável, saturação em bases) que mais diferiram ao longo do perfil edáfico para cada classe de solo definida na área, bem como as respectivas porcentagens de partículas finas (argila + silte) são apresentadas na Tab. 2. O Latossolo Vermelho caracteriza-se como tendo a maior variação das características ao longo do perfil. À superfície, apresenta maior teor em matéria orgânica e textura mais fina, além de menor acidez e menor teor em Al trocável. A saturação por bases também é bem superior na camada superficial, especialmente devida ao $\mathrm{Mg}$. 


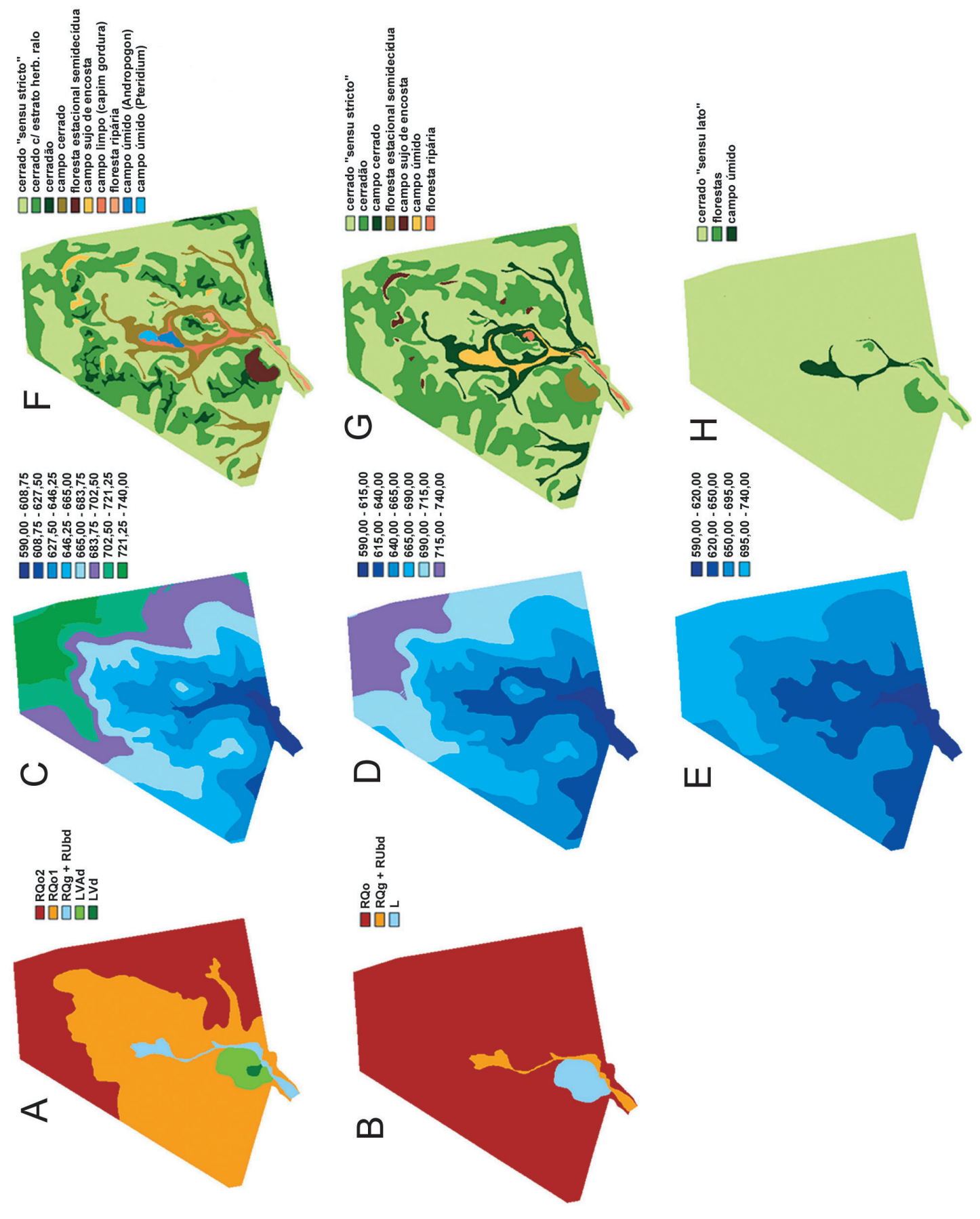

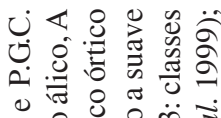

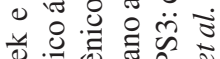

ว

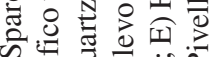

$\circlearrowleft \circ \overrightarrow{0}$

S :

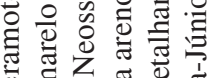

过荌

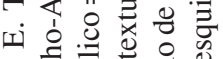

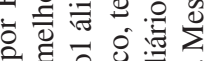

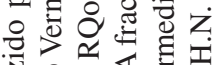

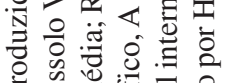

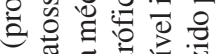

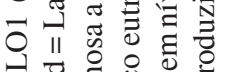

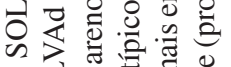

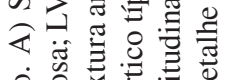

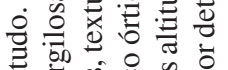

कि

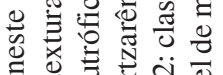

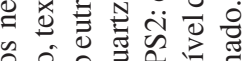

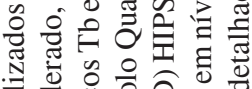

跣

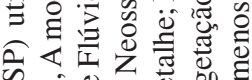

o 0 元

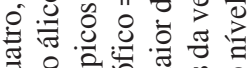

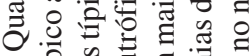

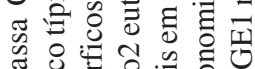

象宽造.

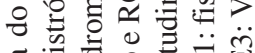

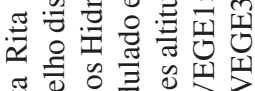

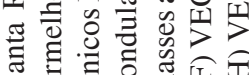

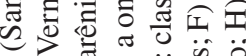

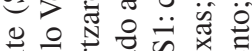

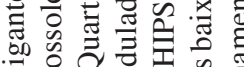

현

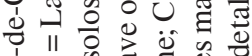

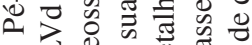

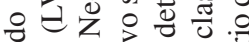

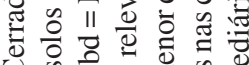

U w

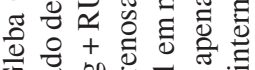

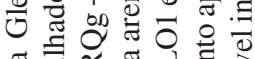

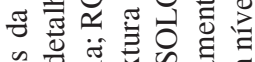

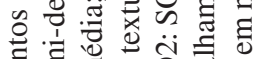

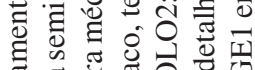

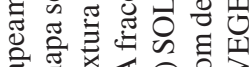

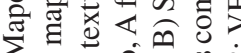

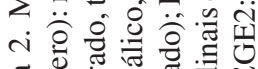

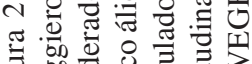

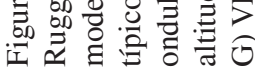


Fica evidenciada também a semelhança física entre os Neossolos Quartzarênicos eutrófico e álico, porém, sua diferença em termos nutricionais. Os Neossolos Hidromórficos e Flúvicos apresentaram propriedades mais constantes ao longo do perfil (Tab. 2).

O conjunto dos mapas temáticos utilizados nos cruzamentos compõe a figura 2. Aqueles que mostraram maior correspondência visualmente foram VEGE3 (Fig. 2H) e SOLO2 (Fig. 2B). Observa-se forte associação entre o cerrado sensu lato e os Neossolos Quartzarênicos, bem como entre os campos úmidos e os Neossolos Hidromórficos típicos e Flúvicos; as florestas encontram-se associadas tanto aos Latossolos como a solos hidromórficos e aluviais.

Todos os mapas se mostraram significativamente associados e correlacionados, com valores de $\chi^{2}$ significativos no nível de $1 \%$ (Tab. 3). Os cruzamentos que apresentaram os maiores valores de $\phi$ para cada conjunto de temas foram: VEGE3 $\times$ SOLO2, $\phi=$ 0,44; VEGE3 $\times$ SOLO1, $\phi=0,44$; VEGE2 $\times$ SOLO2, $\phi=0,52 ;$ VEGE1 $\times$ SOLO2, $\phi=0,54 ;$ VEGE2 $\times$ HIPS3, $\phi=0,39$; VEGE1 $\times$ HIPS3, $\phi=0,39$; VEGE2 $\times$ SOLO1, $\phi=0,39$ (Tab. 3).
Nos cruzamentos dos mapas de solo com os de vegetação, as florestas, e mais especificamente a floresta estacional semidecídua, sempre foram responsáveis pela maior significância do $\chi^{2}$, seguidas do campo úmido (Tab. 4, 5). A floresta estacional semidecídua foi a única fisionomia que se encontrou fortemente associada a uma classe de solo, o Latossolo (Tab. 4; Fig. 2). A associação entre os campos úmidos e os solos hidromórficos e aluviais é evidente e esperada. Os campos úmidos com Andropogon spp. e Pteridium sp. encontram-se relacionados às áreas sob forte influência da rede de drenagem, que sofrem variação temporária do nível do lençol freático, onde ocorrem os Neossolos Hidromórficos e Flúvicos e os Neossolos Quartzarênicos. As fisionomias de cerrado sensu lato apresentaram um padrão semelhante quanto à sua ocorrência em relação às classes de solo, estando em sua grande maioria sobre Neossolos Quartzarênicos, sem distinção entre RQo1 álico e RQo2 eutrófico (Tab. 4, 5; Fig. 2).

Nos cruzamentos com os mapas hipsométricos (Tab. 6), o campo cerrado foi a fisionomia que mais

Tabela 2. Parâmetros químicos e físicos (média e desvio padrão) analisados para o mapeamento dos solos da Gleba Cerrado Pé-deGigante (Santa Rita do Passa Quatro, SP).RQo1 = Neossolo Quartzarênico 1, distrófico e ou álico, A fraco, textura arenos, relevo suave ondulado a ondulado; RQo2 - Neossolo Quartzarênico eutrófico, A fraco, textura arenosa, relevo plano a suave ondulado; RQg + RUbd - Neossolos hidromórficos típicos, eutrófico ou distrófico, textura arenosa a média + Neossolos Flúvicos Tb eutróficos ou distróficos; LVd - Latossolo Vermelho Escuro, álico, A moderado, textura argilosa; LVAd - Latossolo Vermelho Amarelo, álico, A moderado, textura média. (Prof. = profundidade; $\mathrm{SB}=$ soma de bases; $\mathrm{V}=$ saturação por bases; $\mathrm{m}=$ saturação por $\mathrm{Al}$ ).

\begin{tabular}{|c|c|c|c|c|c|c|c|}
\hline Classe de solo & $\begin{array}{l}\text { Prof. } \\
\mathrm{cm}\end{array}$ & $\begin{array}{c}\mathrm{pH} \\
\mathrm{CaCl}_{2}\end{array}$ & $\begin{array}{l}\mathrm{MO} \\
\mathrm{g} / \mathrm{kg}\end{array}$ & $\begin{array}{c}\mathrm{P} \\
\mathrm{mg} / \mathrm{kg}\end{array}$ & $\begin{array}{c}\mathrm{K} \\
\mathrm{mmolc} / \mathrm{kkg}\end{array}$ & $\begin{array}{c}\mathrm{Ca} \\
\mathrm{mmolc} / \mathrm{kkg}\end{array}$ & $\mathrm{Mg}$ \\
\hline \multirow[t]{4}{*}{ RQo1 } & 0 & $3,7 \pm 0,4$ & $23,75 \pm 12,85$ & $5,92 \pm 5,42$ & $1,25 \pm 1,33$ & $8,87 \pm 17,40$ & $2,96 \pm 4,26$ \\
\hline & 5 & $3,9 \pm 0,2$ & $14,74 \pm 9,14$ & $6,39 \pm 12,84$ & $0,93 \pm 0,96$ & $6,83 \pm 11,10$ & $2,30 \pm 2,51$ \\
\hline & 40 & $4,1 \pm 0,1$ & $11,43 \pm 7,53$ & $4,00 \pm 6,02$ & $0,76 \pm 0,84$ & $6,74 \pm 10,10$ & $2,17 \pm 2,19$ \\
\hline & 80 & $4,1 \pm 0,2$ & $11,17 \pm 6,27$ & $3,83 \pm 6,98$ & $0,67 \pm 0,67$ & $4,75 \pm 8,04$ & $1,75 \pm 1,89$ \\
\hline \multirow[t]{4}{*}{ RQo2 } & 0 & $3,7 \pm 0,3$ & $27,07 \pm 13,45$ & $7,67 \pm 6,18$ & $3,10 \pm 0,52$ & $28,47 \pm 7,05$ & $8,20 \pm 2,27$ \\
\hline & 5 & $3,9 \pm 0,1$ & $11,87 \pm 4,17$ & $8,80 \pm 14,00$ & $2,59 \pm 0,30$ & $24,87 \pm 3,46$ & $6,93 \pm 1,03$ \\
\hline & 40 & $4,0 \pm 0,1$ & $5,33 \pm 2,87$ & $6,47 \pm 11,82$ & $2,26 \pm 0,58$ & $23,53 \pm 3,98$ & $6,27 \pm 1,67$ \\
\hline & 80 & $4,1 \pm 0,1$ & $2,50 \pm 1,40$ & $5,40 \pm 8,52$ & $2,31 \pm 0,24$ & $25,00 \pm 3,64$ & $6,43 \pm 0,76$ \\
\hline \multirow[t]{4}{*}{ RQg + RUbd } & 0 & $3,9 \pm 0,2$ & $22,75 \pm 14,50$ & $11,00 \pm 5,35$ & $2,95 \pm 0,37$ & $31,25 \pm 3,30$ & $8,50 \pm 1,29$ \\
\hline & 5 & $3,9 \pm 0,1$ & $4,50 \pm 4,36$ & $5,75 \pm 1,26$ & $2,27 \pm 0,94$ & $21,25 \pm 13,50$ & $6,00 \pm 2,00$ \\
\hline & 40 & $4,0 \pm 0,1$ & $6,00 \pm 4,69$ & $3,00 \pm 0,82$ & $1,97 \pm 1,06$ & $20,75 \pm 13,17$ & $5,50 \pm 2,38$ \\
\hline & 80 & $3,9 \pm 0,1$ & $9,25 \pm 13,86$ & $3,25 \pm 0,50$ & $1,37 \pm 1,13$ & $20,5 \pm 13,00$ & $4,75 \pm 2,50$ \\
\hline \multirow[t]{4}{*}{ LVd } & 0 & $4,4 \pm 0,0$ & $45,00 \pm 5,66$ & $6,00 \pm 0,00$ & $2,35 \pm 0,64$ & $25,50 \pm 7,78$ & $14,00 \pm 0,00$ \\
\hline & 5 & & & & & & \\
\hline & 40 & $4,0 \pm 0,1$ & $10,50 \pm 3,54$ & $2,00 \pm 0,00$ & $0,80 \pm 0,28$ & $6,50 \pm 2,12$ & $3,50 \pm 0,71$ \\
\hline & 80 & $4,0 \pm 0,1$ & $8,00 \pm 0,00$ & $2,50 \pm 0,71$ & $0,75 \pm 0,78$ & $9,50 \pm 6,36$ & $3,50 \pm 0,71$ \\
\hline \multirow[t]{4}{*}{ LVAd } & 0 & $4,4 \pm 0,6$ & $29,11 \pm 10,66$ & $3,89 \pm 0,93$ & $1,46 \pm 0,66$ & $14,44 \pm 12,58$ & $6,89 \pm 5,04$ \\
\hline & 5 & $4,1 \pm 0,1$ & $13,43 \pm 3,41$ & $2,57 \pm 0,98$ & $0,71 \pm 0,30$ & $1,71 \pm 1,89$ & $2,28 \pm 2,14$ \\
\hline & 40 & $4,1 \pm 0,0$ & $8,67 \pm 2,18$ & $2,22 \pm 0,67$ & $0,48 \pm 0,26$ & $1,11 \pm 0,33$ & $1,33 \pm 0,71$ \\
\hline & 80 & $4,2 \pm 0,1$ & $7,44 \pm 4,22$ & $2,00 \pm 0,53$ & $0,36 \pm 0,25$ & $1,00 \pm 0,00$ & $\begin{array}{r}1,11 \pm 0,33 \\
\text { continua }\end{array}$ \\
\hline
\end{tabular}


contribuiu para o aumento do $\chi^{2}$, seguido da floresta ripária. O campo cerrado ocorre preferencialmente em altitudes de 620 a $650 \mathrm{~m}$, e o campo úmido e a floresta ripária, nas menores altitudes $(590-620 \mathrm{~m})$. As formas mais densas de cerrado - cerradão, cerrado com estrato herbáceo ralo e cerrado sensu stricto - encontram-se sobre as maiores altitudes (Tab. 6; Fig. 2). Essas relações entre a vegetação e a topografia, bem como também destas com o solo e as formas de relevo, ficam evidenciadas no perfil topográfico (Fig. 3). Na parte mais baixa, à beira do córrego Paulicéia, onde ocorrem a floresta ripária e os campos úmidos, há condições redutoras durante parte do ano, devido aos alagamentos sazonais temporários, e a ocorrência dos Neossolos Hidromórficos e Flúvicos. Nas partes mais altas e sobre Neossolos Quartzarênicos, onde a drenagem tende a ser intensa, ocorrem as fisionomias de cerrado que têm maior participação do componente arbóreo (cerrado sensu stricto, cerrado com estrato herbáceo ralo e cerradão). A floresta semidecídua também se encontra associada a porções do relevo que permitem boa drenagem, como ocorre nas áreas de Latossolo.

\section{Discussão}

O detalhamento dos mapas pedológicos em subunidades taxonômicas não contribuiu para melhorar significativamente a compreensão da relação entre a vegetação nativa e as classes de solo. Os cruzamentos que apresentaram os maiores valores de $\phi$ foram entre aqueles mapas mais detalhados da vegetação e o de solos em menor detalhe (VEGE1 $\times$ SOLO2 e VEGE2 $\times$ SOLO2). Também foram altos os valores de $\phi$ entre o mapa menos detalhado da vegetação e os dois de solos $($ VEGE3 $\times$ SOLO1 e VEGE3 $\times$ SOLO2) .

$\mathrm{O}$ fato das fisionomias de cerrado sensu lato terem ocorrido indistintamente sobre os Neossolos Quartzarênicos indica que o critério utilizado para dividir esse solo em álico (distrófico) e eutrófico, segundo os valores de saturação por bases, não corresponde às variações fisionômicas da vegetação nativa, nos níveis de detalhe comumente apresentados nos mapas de vegetação (ex.: VEGE1, VEGE2, VEGE3). Da mesma forma, a divisão dos Latossolos em Vermelho e VermelhoAmarelo não correspondeu ao detalhamento das fitofisionomias. No Brasil central, Furley e Ratter (1988)

Tabela 2 (continuação). Parâmetros químicos e físicos (média e desvio padrão) analisados para o mapeamento dos solos da Gleba Cerrado Pé-de-Gigante (Santa Rita do Passa Quatro, SP).RQo1 = Neossolo Quartzarênico 1, distrófico e ou álico, A fraco, textura arenos, relevo suave ondulado a ondulado; RQo2 - Neossolo Quartzarênico eutrófico, A fraco, textura arenosa, relevo plano a suave ondulado; RQg + RUbd - Neossolos hidromórficos típicos, eutrófico ou distrófico, textura arenosa a média + Neossolos Flúvicos Tb eutróficos ou distróficos; LVd - Latossolo Vermelho Escuro, álico, A moderado, textura argilosa; LVAd - Latossolo Vermelho Amarelo, álico, A moderado, textura média. (Prof. = profundidade; $\mathrm{SB}=$ soma de bases; $\mathrm{V}=$ saturação por bases; $\mathrm{m}=$ saturação por $\mathrm{Al}$ ).

\begin{tabular}{|c|c|c|c|c|c|c|}
\hline Classe de solo & $\mathrm{Al}$ & SB & $\mathrm{V}(\%)$ & $\mathrm{m}$ & Areia (\%) & $\begin{array}{l}\text { Silte }+ \text { argila }= \\
\text { partículas finas }\end{array}$ \\
\hline \multirow[t]{4}{*}{ RQo1 } & $10,50 \pm 7,41$ & $13,08 \pm 22,59$ & $14,62 \pm 17,35$ & $59,46 \pm 23,63$ & $88,75 \pm 3,48$ & $11,25 \pm 3,48$ \\
\hline & $9,43 \pm 3,47$ & $10,06 \pm 14,53$ & $14,04 \pm 14,31$ & $62,69 \pm 21,45$ & $88,17 \pm 4,86$ & $11,83 \pm 4,86$ \\
\hline & $6,74 \pm 2,67$ & $9,67 \pm 13,11$ & $20,00 \pm 17,80$ & $55,39 \pm 19,97$ & $86,67 \pm 4,81$ & $13,33 \pm 4,81$ \\
\hline & $6,46 \pm 2,81$ & $7,17 \pm 10,52$ & $17,92 \pm 14,74$ & $58,42 \pm 17,86$ & $85,79 \pm 5,32$ & $14,21 \pm 5,32$ \\
\hline \multirow[t]{4}{*}{ RQo2 } & $13,40 \pm 7,21$ & $39,77 \pm 9,46$ & $38,27 \pm 11,91$ & $24,87 \pm 11,65$ & $89,47 \pm 2,77$ & $10,53 \pm 2,77$ \\
\hline & $11,80 \pm 2,57$ & $34,39 \pm 4,45$ & $46,00 \pm 10,68$ & $25,53 \pm 5,01$ & $88,13 \pm 2,67$ & $11,87 \pm 2,67$ \\
\hline & $8,60 \pm 2,32$ & $32,06 \pm 9,11$ & $50,07 \pm 15,41$ & $23,87 \pm 17,55$ & $87,07 \pm 2,81$ & $12,93 \pm 2,81$ \\
\hline & $7,28 \pm 1,82$ & $33,85 \pm 4,30$ & $56,64 \pm 7,41$ & $17,73 \pm 3,35$ & $85,20 \pm 3,53$ & $14,86 \pm 3,65$ \\
\hline \multirow[t]{4}{*}{ RQg + RUbd } & $13,25 \pm 10,50$ & $42,70 \pm 4,78$ & $50,50 \pm 6,56$ & $22,00 \pm 12,11$ & $84,75 \pm 12,53$ & $15,25 \pm 12,53$ \\
\hline & $13,00 \pm 4,69$ & $29,52 \pm 16,42$ & $40,00 \pm 24,07$ & $36,00 \pm 15,68$ & $81,25 \pm 16,36$ & $18,75 \pm 16,36$ \\
\hline & $12,50 \pm 9,57$ & $28,22 \pm 16,55$ & $37,75 \pm 26,66$ & $34,50 \pm 16,18$ & $82,00 \pm 14,51$ & $18,00 \pm 14,51$ \\
\hline & $13,50 \pm 8,02$ & $20,37 \pm 17,46$ & $38,00 \pm 27,60$ & $55,00 \pm 24,93$ & $75,75 \pm 16,26$ & $15,75 \pm 3,86$ \\
\hline \multirow[t]{4}{*}{$\mathrm{LVd}$} & $6,50 \pm 2,12$ & $41,85 \pm 8,41$ & $40,50 \pm 0,71$ & $13,00 \pm 1,41$ & $62,00 \pm 4,24$ & $38,00 \pm 4,24$ \\
\hline & & & & & $60,00 \pm 1,41$ & $40,00 \pm 1,41$ \\
\hline & $30,00 \pm 5,66$ & $10,80 \pm 3,11$ & $18,50 \pm 4,95$ & $73,50 \pm 9,19$ & $52,50 \pm 0,71$ & $47,50 \pm 0,71$ \\
\hline & $31,50 \pm 9,19$ & $10,75 \pm 12,09$ & $21,50 \pm 6,36$ & $78,00 \pm 16,97$ & $55,50 \pm 9,19$ & $49,50 \pm 2,12$ \\
\hline \multirow[t]{4}{*}{ LVAd } & $4,44 \pm 4,75$ & $22,79 \pm 18,02$ & $32,89 \pm 20,71$ & $27,89 \pm 32,17$ & $81,56 \pm 3,43$ & $18,44 \pm 3,43$ \\
\hline & $7,86 \pm 2,41$ & $4,71 \pm 4,23$ & $10,43 \pm 5,03$ & $65,29 \pm 20,33$ & $80,22 \pm 4,41$ & $19,78 \pm 4,41$ \\
\hline & $8,44 \pm 3,24$ & $2,92 \pm 1,20$ & $10,11 \pm 3,52$ & $73,44 \pm 7,35$ & $76,89 \pm 5,39$ & $23,11 \pm 5,39$ \\
\hline & $9,56 \pm 5,00$ & $2,49 \pm 0,41$ & $10,00 \pm 2,69$ & $74,87 \pm 8,41$ & $77,00 \pm 5,13$ & $24,67 \pm 6,93$ \\
\hline
\end{tabular}


Tabela 3. Valores de Qui-quadrado $\left(\chi^{2}\right)$ obtidos dos 20 cruzamentos, graus de liberdade (GL), $\chi^{2}$ crítico $(\mathrm{p}<0,001)$ e o coeficiente de Cramér $(\phi)$. Em negrito, os maiores valores de f para cada tema de cruzamento.

\begin{tabular}{|c|c|c|c|c|}
\hline Cruzamento & $\chi^{2}$ & GL & $\chi^{2}$ crítico & $\phi$ \\
\hline Vegetação $1 \times$ solo 1 & 81204 & 36 & 67,98 & 0,41 \\
\hline Vegetação $1 \times$ solo 2 & 72653 & 18 & 42,31 & 0,54 \\
\hline Vegetação $2 \times$ solo 1 & 75784 & 24 & 51,18 & 0,39 \\
\hline Vegetação $2 \times$ solo 2 & 67340 & 12 & 32,91 & 0,52 \\
\hline Vegetação $3 \times$ solo 1 & 47456 & 8 & 26,12 & 0,44 \\
\hline Vegetação $3 \times$ solo 2 & 46830 & 4 & 18,47 & 0,44 \\
\hline Vegetação 1 × hipsométrico 1 & 81145 & 63 & 103,44 & 0,31 \\
\hline Vegetação $1 \times$ hipsométrico 2 & 70821 & 45 & 80,08 & 0,34 \\
\hline Vegetação $1 \times$ hipsométrico 3 & 56483 & 27 & 55,48 & 0,39 \\
\hline Vegetação $2 \times$ hipsométrico 1 & 74897 & 49 & 85,35 & 0,32 \\
\hline Vegetação $2 \times$ hipsométrico 2 & 68492 & 30 & 59,70 & 0,33 \\
\hline Vegetação $2 \times$ hipsométrico 3 & 54531 & 18 & 42,31 & 0,39 \\
\hline Vegetação 3 v hipsométrico 1 & 19654 & 14 & 36,12 & 0,28 \\
\hline Vegetação $3 \times$ hipsométrico 2 & 19247 & 10 & 29,59 & 0,28 \\
\hline Vegetação $3 \times$ hipsométrico 3 & 12782 & 6 & 22,46 & 0,23 \\
\hline
\end{tabular}

identificaram dois tipos de cerradão floristicamente mas não fisionomicamente distintos, relacionados a manchas de solos mesotróficos e distróficos. Também Ruggiero et al. (2002) identificaram, por meio de análise multivariada, dois tipos florísticos de floresta semidecídua na Gleba Cerrado Pé-de-Gigante, sem que diferissem floristicamente.

As relações mais claras entre tipo de solo e fisionomia de vegetação se deram entre os Latossolos e a floresta semidecídua, bem como entre formações associadas a solos hidromóficos - sendo, neste caso, a água o principal determinante. Entretanto, a ocorrência de cerradão, além da floresta semidecídua, sobre Latossolo Vermelho-Amarelo mostra que essas duas fitofisionomias não são condicionadas exclusivamente pelas características edáficas utilizadas para a classificação de solos, fato já demonstrado por Ratter e colaboradores (Ratter et al. 1977) em fragmentos de cerrado do Brasil central, mas nunca antes verificado em áreas contíguas, como neste estudo.

Tabela 4. Tabela de contingência gerada a partir dos cruzamentos VEGE1 × SOLO2; VEGE2 × SOLO2; VEGE3 × SOLO2, indicando a porcentagem de área ocupada pela fitofisionomia em cada classe de solo. $\mathrm{O}$ asterisco indica a fitofisionomia que mais contribuiu para a significância do $\chi^{2}$. (VEGE1, VEGE2 e VEGE3= classificações da vegetação; SOLO2 = classificação do solo, ver explicações no texto).

Classe da vegetação: VEGE1
Classe do solo: $\mathrm{SOLO} 2$

\begin{tabular}{ccc}
\hline RQo: Neossolos & RQg + RUbd: Neossolos & L: Latossolos \\
Quartzarênicos & Hidromórficos típicos e & \\
& Flúvicos Tb eutróficos &
\end{tabular}

\begin{tabular}{|c|c|c|c|}
\hline Cerrado sensu stricto & 47,04 & 0,76 & 1,08 \\
\hline Cerrado com estrato herbáceo ralo & 32,19 & 0,01 & 0,86 \\
\hline Cerradão & 3,89 & 0,00 & 0,12 \\
\hline Campo cerrado & 8,57 & 0,71 & 0,06 \\
\hline Floresta estacional* & 0,00 & 0,00 & 1,31 \\
\hline Campo sujo de encosta & 0,82 & 0,00 & 0,00 \\
\hline Campo limpo & 0,92 & 0,33 & 0,00 \\
\hline Floresta ripária & 0,38 & 0,24 & 0,00 \\
\hline Campo úmido de Andropogon spp. & 0,07 & 0,36 & 0,00 \\
\hline Campo de Pteridium sp. & 0,17 & 0,12 & 0,00 \\
\hline \multicolumn{4}{|l|}{ Classe de vegetação: VEGE2 } \\
\hline Cerrado sensu stricto & 47,04 & 0,76 & 1,08 \\
\hline Cerradão & 36,08 & 0,01 & 0,98 \\
\hline Campo cerrado & 8,57 & 0,71 & 0,06 \\
\hline Floresta estacional* & 0,00 & 0,00 & 1,31 \\
\hline Campo sujo de encosta & 0,82 & 0,00 & 0,00 \\
\hline Campo úmido & 1,16 & 0,81 & 0,00 \\
\hline Floresta ripária & 0,38 & 0,24 & 0,00 \\
\hline \multicolumn{4}{|l|}{ Classe de vegetação: VEGE3 } \\
\hline Cerrado sensu lato & 92,51 & 1.48 & 2,11 \\
\hline Florestas* & 0,38 & 0.24 & 1,32 \\
\hline Campo úmido & 1,16 & 0,81 & 0.00 \\
\hline
\end{tabular}


Tabela 5. Tabela de contingência gerada a partir do cruzamento VEGE3 $\times$ SOLO1, indicando a porcentagem de área ocupada pela fitofisionomia em cada classe de solo. O asterisco indica a fitofisionomia que mais contribuiu para a significância do $\chi^{2}$. (VEGE3 = classificação da vegetação; SOLO1 = classificação do solo, ver explicações no texto).

\begin{tabular}{lccccc}
\hline \multirow{2}{*}{$\begin{array}{l}\text { Classe de vegetação: } \\
\text { VEGE3 }\end{array}$} & $\begin{array}{c}\text { RQo1 álico: } \\
\text { Neossolo } \\
\text { Quartzarênico 1 }\end{array}$ & $\begin{array}{c}\text { RQo2 eutrófico: } \\
\text { Neossolo } \\
\text { Quartzarênico 2 }\end{array}$ & $\begin{array}{c}\text { RQg + RUbd: Neossolos } \\
\text { Hidromórficos típicos e } \\
\text { Flúvicos Tb eutróficos }\end{array}$ & $\begin{array}{c}\text { LVAd: } \\
\text { Latossolo } \\
\text { Vermelho-Amarelo }\end{array}$ & $\begin{array}{c}\text { Latossolo } \\
\text { Vermelho }\end{array}$ \\
\hline Cerrado sensu lato & 39,87 & 52,64 & 1,48 & 1,94 \\
Florestas* & 0,00 & 0,38 & 0,24 & 0,17 \\
Campo úmido & 0,05 & 1,11 & 0,81 & 0,12 \\
\hline
\end{tabular}

Tabela 6. Tabela de contingência gerada a partir dos cruzamentos VEGE1 × HIPS3 e VEGE2 × HIPS3, indicando a porcentagem de área ocupada pela fitofisionomia em cada classe altitudinal. O asterisco indica a fitofisionomia que mais contribuiu para a significância do $\chi^{2}$. (VEGE1 e VEGE2 = classificações da vegetação; HIPS3 = classificação da hipsometria, ver explicações no texto).

\begin{tabular}{|c|c|c|c|c|}
\hline \multirow[b]{2}{*}{ Classe de vegetação: VEGE1 } & \multicolumn{4}{|c|}{ Classe altitudinal (m): HIPS3 } \\
\hline & $590-620$ & $620-650$ & $650-695$ & $695-740$ \\
\hline Cerrado sensu stricto & 2,11 & 11,01 & 23,23 & 12,53 \\
\hline Cerrado com estrato herbáceo ralo & 0,07 & 1,89 & 17,90 & 13,18 \\
\hline Cerradão & 0,00 & 0,00 & 2,91 & 1,09 \\
\hline Campo cerrado* & 0,76 & 7,18 & 1,40 & 0,00 \\
\hline Floresta estacional & 0,00 & 1,07 & 0,24 & 0,00 \\
\hline Campo sujo de encosta & 0,00 & 0,00 & 0,12 & 0,70 \\
\hline Campo limpo & 0,35 & 0,90 & 0,00 & 0,00 \\
\hline Floresta ripária & 0,48 & 0,14 & 0,00 & 0,00 \\
\hline Campo úmido de Andropogon spp. & 0,00 & 0,43 & 0,00 & 0,00 \\
\hline Campo de Pteridium sp. & 0,00 & 0,29 & 0,00 & 0,00 \\
\hline \multicolumn{5}{|l|}{ Classe de vegetação: VEGE2 } \\
\hline Cerrado sensu stricto & 2,11 & 11,01 & 23,23 & 12,53 \\
\hline Cerradão & 0,07 & 1,90 & 20,81 & 14,27 \\
\hline Campo cerrado* & 0,76 & 7,18 & 1,40 & 0,00 \\
\hline Floresta estacional & 0,00 & 1,07 & 0,24 & 0,00 \\
\hline Campo sujo de encosta & 0,00 & 0,00 & 0,12 & 0,70 \\
\hline Campo úmido & 0,35 & 1,62 & 0,00 & 0,00 \\
\hline Floresta ripária & 0,48 & 0,14 & 0,00 & 0,00 \\
\hline
\end{tabular}

Para este mesmo fragmento de cerrado, Ruggiero et al. (2002) encontraram que a maior quantidade de argila ao longo do perfil de solo e a concentração de $\mathrm{Al}, \mathrm{P}, \mathrm{Ca}$ e $\mathrm{Mg}$, especialmente na camada superficial, estavam associados à separação das florestas e do cerrado sensu lato. O presente estudo mostra teores de Ca em Neossolo Quartzarênico eutrófico superiores aos dos Latossolos, ao longo de todo o perfil, sem que a floresta semidecídua ocorra sobre o Neossolo Quartzarênico. No caso do Mg, o Latossolo Vermelho apresentou quantidades bem superiores apenas na superfície, o que praticamente igualou a saturação por bases na superfície desses dois solos. No restante do perfil, porém, a saturação por bases manteve-se muito superior no Neossolo Quartzarênico eutrófico, em comparação com o Latossolo Vermelho. Assim, manteve-se aqui, tal como verificado por Ruggiero et al. (2002), uma grande diferenciação nas condições químicas da camada superficial do Latossolo Vermelho, onde se concentra a floresta semidecídua, em termos de $\mathrm{Al}$ trocável, $\mathrm{pH}$ e teor em matéria orgânica, além do Mg. É possível que esses parâmetros tenham grande influência no estabelecimento das plântulas, selecionando espécies típicas de floresta ou de cerrado sensu lato num ou noutro solo.

$\mathrm{O}$ fato das diferentes fisionomias de cerrado sensu lato - cerradão, cerrado com estrato herbáceo ralo, cerrado sensu stricto e campo cerrado - não terem 


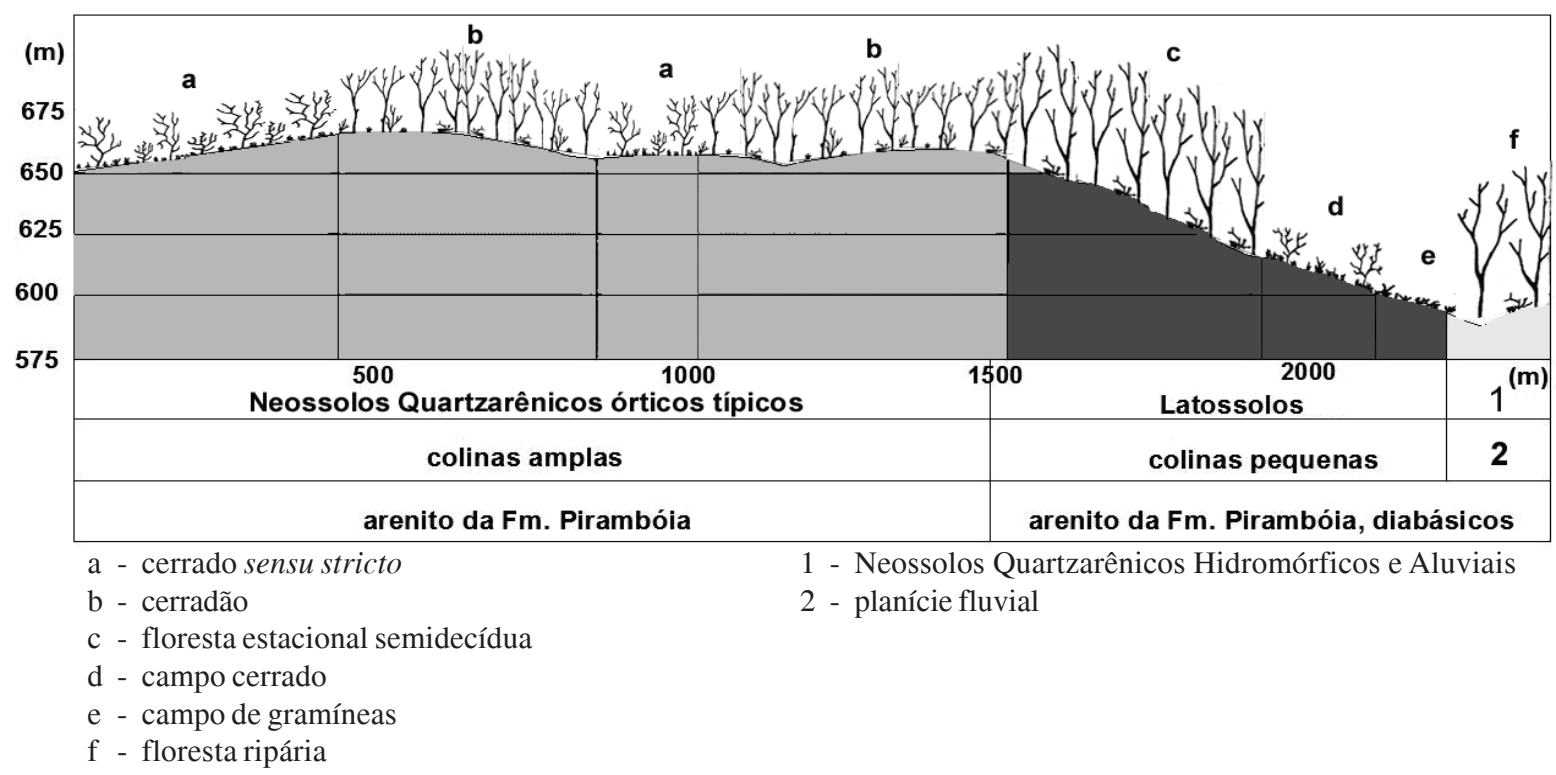

Figura 3. Perfil esquemático de um trecho da Gleba Cerrado Pé-de-Gigante (Parque Estadual de Vassununga, Santa Rita do Passa Quatro, SP), representando vegetação, solo, topografia e substrato geológico.

mostrado relação clara com classes de solo e nem com a fertilidade, como também demonstrado por Ruggiero et al. (2002) para esta mesma área e por outros autores (Gibbs et al. 1983; Haridasan 1992), para outras regiões, indica que sejam determinadas por uma combinação mais complexa de fatores, onde a variação de água subterrânea é, provavelmente, importante. Por exemplo, o campo cerrado apresentou alta associação com a topografia, ocorrendo sempre entre 620 e $650 \mathrm{~m}$, nos pés de encostas de morros e colinas. Para Furley (1999), o campo cerrado ocorre onde a drenagem vertical e lateral é rápida, mesmo durante intensas precipitações da época chuvosa, e onde o lençol freático eventualmente consegue atingir a superfície, não afetando o crescimento da vegetação herbácea, mas limitando o desenvolvimento de elementos lenhosos. Essa deve ser a causa mais provável para a ocorrência do campo cerrado numa situação topográfica específica, na Gleba Cerrado Pé-de-Gigante, o qual deve estar sendo influenciado pela dinâmica da água em sub-superfície. Também para a floresta ripária e os campos úmidos, a forte associação com as menores altitudes decorre da presença de água (córrego Paulicéia), porém, causando encharcamento do solo por períodos mais prolongados.

Assim, a consideração isolada de características pedológicas ou da topografia não permite explicar satisfatoriamente a distribuição das fisionomias de vegetação na área estudada. No entanto, quando considerados concomitante, esses aspectos permitem evidenciar processos que podem condicionar a distribuição da vegetação.

A informação contida nas classes de vegetação em diferentes níveis de detalhe não coincidiu com aquela das classes de solo e topografia em níveis de detalhe correspondentes. O detalhamento da informação mapeada não garantiu melhores resultados à sua interpretação, pois as classes fitofisionômicas não respondem diretamente, nem isoladamente, à topografia ou às classes de solo usualmente utilizadas.

As classificações usuais da vegetação e do solo para a produção de mapas seguem critérios com diferentes objetivos. Os critérios para a classificação do solo visam aos fins agrícolas (EMBRAPA 1999), enquanto que os critérios para a classificação da vegetação geralmente visam subsidiar estratégias e leis de manejo florestal (Sun et al. 1997). Se as comunidades vegetais naturais não respondem aos parâmetros do solo considerados importantes para a agricultura, há uma baixa correspondência entre os mapeamentos de vegetação e de solos, mesmo que em níveis de detalhamento correspondentes. Isso provavelmente não ocorreria se houvesse uma classificação de solos dirigida à vegetação nativa, com base em critérios que refletissem seus processos funcionais.

Além dos próprios critérios de classificação, a delimitação de fronteiras discretas para variáveis contínuas, como é geralmente a vegetação natural, implica em distorção e em acúmulo de erros 
provenientes do próprio mapeamento. Por isso, mapas que representam o espectro contínuo de variação do objeto de estudo - que geralmente incorporam técnicas de geoestatística e análise multivariada - são instrumentos mais eficientes para a compreensão dos sistemas naturais (Burrough et al. 1977; Rijt et al. 1996; Pan et al. 1998).

\section{Agradecimentos}

Agradecemos à FAPESP (Fundação de Amparo à Pesquisa do Estado de São Paulo), pelo financiamento desta pesquisa; ao técnico Paulo César Fernandes, do Departamento de Ecologia da Universidade de São Paulo, pela colaboração no trabalho de campo; ao Dr. M. Haridasan, pelas excelentes sugestões dadas na qualidade de revisor do manuscrito.

\section{Referências bibliográficas}

Alvim, P.T. \& Araújo, W.A. 1952. El suelo como factor ecológico en el desarrolo de la vegetación en el centrooeste del Brasil. Turrialba 2(4): 153-160.

Batalha, M.A.; Mantovani, W. \& Mesquita Jr., H.N. 2002. Vegetation stucture in cerrado physiognomies in southeastern Brazil. Brazilian Journal of Biology 61: 475-483.

Bitencourt, M.D. \& Pivello, V.R. 1998. SIG e sensoriamento remoto orbital auxiliando o zoneamento ecológico. Investigaciones Geograficas Boletín 36: 35-43.

Burrough, P.A. 1995. Spatial aspects of ecological data. In: R.H.G. Jongman; C. J. F. Ter Braak \& O.F.R. Van Tongeren, (eds.). Data analysis in community and landscape ecology. UK, Cambridge University Press.

Burrough, P.A.; Brown, L. \& Morris, E.C. 1977. Variations in vegetation and soil pattern across the Hawkesbury Sandstone Plateau from Barren Grounds to Fitzroy Falls, New South Wales. Australian Journal of Ecology 2: 137-159.

Camargo, O.A.; Moniz, A.C.; Jorge, J.A. \& Valadares, J.M.A.S. 1986. Métodos de análise química e física de solos. Campinas, Instituto Agronômico do Estado de São Paulo (Bol. Tec. 106).

Castro, A.A.J.F.; Martins, F.R.; Tamashiro, J.Y. \& Shepherd, G.J. 1999. How rich is the flora of Brazilian Cerrados? Annals of Missouri Botanical Garden 86: 192-221.

Cole, M.M. 1982. The influence of soils, geomorphology and geology on the distribution of plant communities in savanna ecosystems. Pp. 145-174. In: B.J. Huntley \& B.H. Walker (eds.). Ecology of Tropical Savannas. Berlin, Springer-Verlag.

Cole, M.M. 1986. The Savannas - Biogeography and Geobotany. London, Academic Press.

Coutinho, L.M. 1978. O conceito de cerrado. Revista Brasileira de Botânica 1: 17-23.
DER (Departamento de Estradas de Rodagem) s.d. Planta da rodovia SP-330, trecho Limeira - Ribeirão Preto (escala 1:20.000, redução de planta 1:2.000), plantas 7 e 8 de 58 .

Eiten, G. 1987. Physiognomic categories of vegetation. Pp. 387-403. In: A. Miyawaki; A. Bogenrieder; S. Okuda \& J. White (eds.). Vegetation Ecology and Creation of New Environments. Tokio, Tokai University Press.

EMBRAPA - Empresa Brasileira de Pesquisa Agropecuária. 1999. Sistema brasileiro de classificação de solos. Brasília, Embrapa.

Furley, P.A. 1996. The influence of slope on the nature and distribution of soils and plant communities in the central Brazilian cerrado. Advances in Hillslope Processes 1(15): 327-345.

Furley, P.A. 1999. The nature and diversity of neotropical savanna vegetation with particular reference to the Brazilian cerrados. Global Ecology and Biogeography 8: 223-241.

Furley, P.A. \& Ratter, J.A. 1988. Soil resources and plant communities of the central Brazilian cerrado and their development. Journal of Biogeography 15: 97-108.

Gibbs, P.E.; Leitão Filho, H.F. \& Shepherd, G. 1983. Floristic composition and community structure in an area of Cerrado in SE Brazil. Flora 173: 433-449.

Goodland, R. \& Pollard, R. 1973. The Brazilian cerrado vegetation: a fertility gradient. Journal of Ecology 61: 219-224.

Haridasan, M. 1992. Observations on soils, foliar nutrients concentrations and floristic composition of cerrado sensu stricto and cerradão communities in central Brazil. In: P.A. Furley; J. Proctor \& J.A. Ratter (eds.). Nature and Dynamics of forest-savanna boundaries. UK, Chapman \& Hall.

IBGE - Instituto Brasileiro de Geografia e Estatística. 1971. Carta do Brasil (escala 1:50.000), Luiz Antônio, Folha SF-23-V-C-IV-2.

IDRISI Production. 1997. IDRISI for windows version 2.0. Clark Labs for Cartographic Technology and Geographic Analysis. USA, Clark University, Worcester, MA.

IGC - Instituto Geográfico e Cartográfico do Estado de São Paulo. 1990. Plano Cartográfico do Estado de São Paulo (escala 1:10.000), Folhas Córrego Água Santa, SF-23-VC-IV-2-SO-B e, Ribeirão Vassununga SF-23-V-C-IV-2NO-F.

Köppen, W. 1948. Climatologia. Fondo de Cultura Económica, México.

Kraak, M.J. \& Ormeling, F.J. 1996. Cartography visualization of spatial data. Inglaterra, Longman Publishers, Harlow.

Martins, F.R. 1982. O balanço hídrico seqüencial e o caráter semidecíduo da floresta do Parque Estadual de Vassununga, Santa Rita do Passa Quatro (SP). Revista Brasileira de Estatística 43(170): 353-391.

Oliveira, J.B.; Jacomine, P.K.T. \& Camargo, M.N. 1992. Classes Gerais de Solos do Brasil - Guia para Auxiliar seu Reconhecimento. Jaboticabal, Funep. 
Oliveira Filho, A.T. \& Martins, F.R. 1986. Distribuição, caracterização e composição florística das formações vegetais da região da Salgadeira, na Chapada dos Guimarães, MT. Revista Brasileira de Botânica 9: 207-223.

Oliveira Filho, A.T.; Shepherd, G.J.; Martins, F.R. \& Stubbleline, W.H. 1989. Environmental factors effecting physiognomic and floristic variation in area of cerrado in central Brazil. Journal of Tropical Ecology 5: 413-431.

Oliveira Filho, A.T.; Curi, N.; Vilela, E.A. \& Carvalho, D.A. 1997. Tree species distribution along soil catenas in a riverside semideciduous forest in the southeastern Brazil. Flora 192: 47-64.

Pan, D.; Bouchard, A.; Legendre, P. \& Domon, G. 1998. Influence of edaphic factors on the spatial structure of inland halophytic communities: a case study in China. Journal of Vegetation Science 9: 797-804.

Pivello, V.R.; Bitencourt, M.D.; Mesquita Júnior, H. N. \& Batalha, M.A. 1999. Banco de dados em SIG para ecologia aplicada: exemplo do Cerrado Pé-de-Gigante, SP. Caderno de Informações Georreferenciadas - CIG, 1(3), artigo 4. (http://www.cpa.unicamp.br/revista/cigv1n3a4.html).

Raij, B.; Quaggio, J.A.; Cantarella, H.; Ferreira, M.E.; Lopes, A.S. \& Bataglia, O.C. 1987. Análise química de solos para fins de fertilidade. Campinas, Fundação Cargill.

Ratter, J.A.; Askew, G.P.; Montgomery, R.F. \& Gifford, D.R. 1977. Observações adicionais sobre o cerradão de solos mesotróficos no Brasil Central. Pp. 303-316. In: M.G. Ferri (coord.). IV Simpósio sobre o cerrado. São Paulo, EDUSP.
Rijt, C.W.C.J.; Hazelhoff, L. \& Blom, C.W.P.M. 1996. Vegetation zonation in a former tidal area: a vegetationtype response model based on DCA and logistic regression using GIS. Journal of Vegetation Science 7: 505-518.

Ruggiero, P.G.C.; Batalha, M.A.; Pivello, V.R. \& Meirelles, S.T. 2002. Vegetation-soil relationships in cerrado (Brazilian savanna) and semideciduous forest, Southeastern Brazil. Plant Ecology 160: 1-16.

Silva Júnior, M.C.; Barros, M.F. \& Cândido, J.F. 1987. Relações entre parâmetros do solo e da vegetação de cerrado na Estação Florestal de Experimentação de Paraopeba, MG. Revista Brasileira de Botânica 10: 125-137.

Sun, D.; Hnatiuk, R.J. \& Neldner, V.J. 1997. Review of vegetation classification and mapping systems undertaken by major forested land management agencies in Australia. Australian Journal of Botany 45: 929-948.

U.S. Dept. Agriculture 1994. Munsell Soil Color Charts. New York, U.S. Dept. Agriculture, Macbeth Division of Kollmorgen Instruments.

Walter, H. 1986. Vegetação e Zonas Climáticas. São Paulo, EPU.

Zar, J. 1999. Biostatistical Analysis. New Jersey, PrenticeHall. 